\title{
Development of Gene Therapy for Immunodeficiency: Adenosine Deaminase Deficiency
}

\author{
R. MICHAEL BLAESE \\ Cellular Immunology Section, Metabolism Branch, National Cancer Institute, National Institutes of Health, \\ Bethesda, Maryland 20892
}

\begin{abstract}
Deficiency of adenosine deaminase (ADA) results in severe combined immunodeficiency. Clinical cure has been observed in several ADA-severe combined immunodeficiency patients after bone marrow transplantation in which only donor $T$ cells were engrafted, suggesting that T-cell correction alone is sufficient for full immune reconstitution. Children without an HLA-matched donor have been treated with polyethylene glycol-ADA as enzyme replacement therapy, resulting in varying degrees of immunologic and clinical improvement. In September 1990, we began treating a 4-y-old girl with periodic infusions of autologous culture-expanded $T$ cells genetically corrected by insertion of a normal ADA gene using retroviral-mediated gene transfer with the LASN vector. After 2 y of polyethylene glycol-ADA treatment and before gene therapy, she continued to experience recurrent infections, was anergic and lymphopenic, and was deficient in isohemagglutinins. After seven infusions totaling $7 \times 10^{10} \mathrm{~T}$ cells, she has demonstrated a substantial increase in the number of circulating $\mathrm{T}$ cells $(571 / \mu \mathrm{L}$ pre-gene therapy versus a mean of $1995 / \mu \mathrm{L}$ with gene therapy infusions every 6-8 wk) and the ADA activity in her peripheral blood $T$ cells has increased $>\mathbf{1 0}$-fold. The increase in $\mathrm{T}$-cell numbers and ADA activity has been associated with the development of positive delayed-type hypersensitivity skin tests, a significant increase in the level of isohemagglutinins, the regrowth of tonsils, and a decreased number of infectious illnesses. This improvement has persisted during suspension of treatment for more than 6 mo. A second patient treated since February 1991 has shown similar improvement in immune status. Both patients have tolerated the treatments without complication and are able to participate fully in school and social activities. These findings demonstrate that infusions of polyclonal autologous $T$ cells metabolically corrected by ADA gene transfer can be an effective treatment for some children with ADA-severe combined immunodeficiency. (Pediatr Res 33 (Suppl): S49-S55, 1993)
\end{abstract}

\section{Abbreviations}

ADA, adenosine deaminase

dAdo, deoxyadenosine

PBMC, peripheral blood mononuclear cells

SCID, severe combined immunodeficiency

PEG, polyethylene glycol

Correspondence: Michael Blaese, M.D., Building 10, Room 6B05, National Institutes of Health, Bethesda, MD 20892.
Gene therapy is often thought of as the ideal treatment for many inherited diseases (1). The prospect of correcting inherited defects by the insertion of a normal copy of the involved gene into the cells of the patient, restoring those cells to normal function, may offer the only effective treatment for some diseases. In practice, the challenges of this approach have proven to be formidable, but finally early progress in clinical application is being made.

The development of gene therapy for any genetic disease first requires the identification and cloning of the gene responsible for that condition. Of the primary immunodeficiency diseases recognized by the World Health Organization (2), the genes for only four have so far been cloned (ADA deficiency, purine nucleoside phosphorylase deficiency, chronic granulomatous disease, and leukocyte adhesion defect). Once the gene has been isolated, its function must be understood before work can begin on developing a method to deliver that gene to the proper cells. This gene delivery may have to be at a specific time during cellular development, and the gene may need to be expressed in a specific geographic location within the cell. It may be necessary to provide for tightly regulated expression of the gene depending on the cell's position in the cell cycle or to respond to critical intracellular messenger molecules. It might be necessary to coordinate the timing and level of expression of the inserted gene with that of other genes within the cell. In addition, it may be necessary to achieve very high efficiency gene transfer lest the residual defective "noncorrected" cells interfere with or limit the effectiveness of the genetically cured cells. If the corrected cells do not have an intrinsic survival advantage over the defective cells, it may also be necessary to use cytoreductive treatment to eliminate the residual defective cells. If the gene defect results in the production of a pathologic gene product (e.g. sickle $\mathrm{Hb})$, a procedure to shut off production of this abnormal gene product must be developed in addition to one inducing production of the correct gene product.

These factors can present significant obstacles to development of gene therapy for many inherited diseases. Unfortunately, this essential scientific base has not developed sufficiently to permit gene therapy for most of the 4000 inherited diseases thus far identified. The primary immunodeficiency diseases as a group lend themselves more readily to gene therapy than most other categories of disease. In theory, any genetic disease that can be successfully reconstituted by allogeneic bone marrow transplantation should be amenable to genetic correction of the patient's own bone marrow stem cell population (3). Bone marrow gene therapy has the advantage that the diseased tissue can be removed from the body for treatment ex vivo, permitting concentrated efforts on targeting gene delivery to the stem cell and avoiding possible delivery of genes to the reproductive tissues. This should ensure that somatic cells alone will be gene modified.

The ex vivo approach has several other advantages. It permits the use of gene transfer techniques that simply would not be 
possible to apply systemically (e.g. electroporation). Ex vivo treatment also potentially allows various selection procedures for gene-modified cells to be used (e.g. G418 selection for NeoR gene function). Finally, ex vivo treatment can provide some opportunity for safety testing of the gene-modified cells before their reimplantation into the patient.

Cloning of the involved gene is just one step in developing gene therapy for a specific disease. The function of that gene and its product must be thoroughly understood before a rational plan can be devised for genetic correction. Some genes may encode for developmentally critical factors that must be active during embryonic/fetal growth for the proper cells to differentiate. In that case, it just may not be possible to functionally correct the disease in postnatal life because potentially responsive precursor cells or differentiative signals from other cells in the environment are no longer available. Other genes could encode for products that are under very close physiologic regulation (e.g. insulin), and those regulatory components might have to be replaced in conjunction with the defective gene. The best initial candidates for gene therapy would be diseases involving a relatively simple "housekeeping" gene that does not require close regulation and whose function is not absolutely critical to the differentiation and development of the affected cell lineage.

For a corrective gene to be inserted into the lymphohematopoietic stem cell, a process that will give highly efficient stable integration of the inserted gene must be a major feature of the transfer system. Otherwise, as the stem cell proliferates and differentiates, the inserted gene could be progressively diluted out and eventually lost from, or unevenly distributed in, the mature erythroid, myeloid, and lymphoid lineages. Gene insertion into a terminally differentiated, nonproliferative tissue such as skeletal muscle or liver might not need integration as a feature of the gene transfer system. Because the immune system so extensively involves cells that proliferate actively during differentiation and also as a consequence of later activation, an integrated gene is probably essential for this population and techniques to provide this feature are the focus of most studies.

The Moloney murine leukemia-based retroviral vectors have distinct advantages for gene therapy of proliferating tissues like the lymphoid system (4). Most importantly, these vectors integrate into the chromosomes of the target cell and thereafter become a stable part of the inheritance of that cell, being passed along to all cell progeny during normal cell division. In addition, retroviral vector systems can be highly efficient for gene transfer, exceeding $90 \%$ in some cell types in vitro. Potential disadvantages of retroviral vectors include the fact that they randomly integrate into the host cell genome, which could have several unfavorable consequences. Random integration implies that each individual transduced cell could behave differently from another cell with a different vector integration site. The local environment of the chromosome where integration occurs (chromatin structure?) may greatly influence the level of gene expression achieved for the inserted gene. For example, Kantoff et al. (5) have found ADA gene expression to vary by more than 100 -fold from clone to clone of retroviral vector-transduced $\mathrm{T}$ cells. For many functional gene systems, this very wide range of gene expression from cell to cell is not acceptable.

Finally, retroviral vectors only integrate their genes into cells that are actively proliferating and synthesizing DNA. The totipotent bone marrow stem cells, the preferred targets for immune precursor gene therapy, are generally not actively proliferating but rather are in a $\mathrm{G}_{0}$ state. Therefore, before retroviral vectors can be effective in inserting genes into these stem cells, manipulations to induce stem cell proliferation must be applied (6).

\section{TRANSPLANTATION FOR IMMUNODEFICIENCY}

Because bone marrow can be treated easily ex vivo, diseases that can be treated by allogeneic bone marrow transplantation have become the leading candidates for the initial attempts at gene therapy for inherited disease. If a child with SCID has an HLA-matched sibling donor, marrow transplantation often does not require preparative cytoablation to enhance engraftment (7). This may occur because the lymphoid progeny of the engrafted normal bone marrow stem cells have a selective growth advantage in vivo over the genetically defective lymphoid cells so that the donor cells come to predominate. Unfortunately, such a selective growth advantage is not found in all immunodeficiency diseases (e.g. Wiskott Aldrich syndrome). Autologous stem cell gene therapy for diseases without such a selective growth advantage will probably require preparative cytoreduction to allow sufficient engraftment of the genetically corrected cells to achieve full reconstitution. The need for cytoreduction will increase the morbidity and mortality of the procedure as it does with conventional bone marrow transplantation. However, gene therapy with autologous cells will still have the advantage of a very low risk of graft-versus-host disease.

Stem cell gene modification has been under intensive investigation in many laboratories. Initial interest centered on the hemoglobinopathies as candidate diseases for gene therapy, with globin gene transfer with retroviral vectors the primary goal (1). In murine systems, several genes have been successfully transferred to the hemopoietic stem cells, resulting in long-term expression in animals that have undergone transplantation.

Unfortunately, attempts to duplicate these results in larger animals were unsuccessful (8). The SAX retroviral vector was found to readily introduce a corrective ADA gene into cultured human ADA- T cells in vitro. However, when the same vector was used to treat freshly collected bone marrow from rhesus or cynomologus monkeys that had been lethally irradiated before reconstitution by transplantation with the "gene-treated" autologous marrow, different results were obtained. Some recipients did produce human ADA in their circulating PBMC, but the level of gene expression was low and disappeared within a few weeks to months (9). Although these studies were disappointing in that stable, long-term gene expression was not achieved, they did demonstrate that retroviral vectors could transfer genes into primate cells and that some gene expression could be detected in peripheral cells after bone marrow treatment. In addition, the gene transfer procedure appeared to be safe in that no complications related to the use of gene-modified cells were observed.

Among the factors that contribute to the failure of these experiments, one is the fact that totipotent stem cells are usually in a nonproliferative $\left(\mathrm{G}_{0}\right)$ state, whereas the retroviral gene transfer system used is only effective in introducing genes into proliferating cells. Thus, genes were probably introduced into a more mature proliferating progenitor population that gave transient expression of the gene before the cells reached senescence, only to be replaced by more primitive cells that had not been in cycle earlier and thus had not acquired the gene. Two strategies have been followed in an attempt to improve these results: $l$ ) the use of growth factors to induce the totipotent stem cells to proliferate, and 2) procedures to enrich the stem cells in the population exposed to the retroviral vector. In addition, we began a series of studies exploring the use of alternative cellular vehicles for gene therapy, specifically $\mathrm{T}$ lymphocytes. These studies in rodents and monineys did demonstrate that mature peripheral $\mathrm{T}$ cells could be successfully modified by retroviral-mediated gene transfer and that the gene-modified cells persisted for prolonged periods and continued to express the introduced genes when reinfused into the donor animals.

\section{ADA DEFICIENCY}

ADA deficiency is inherited as an autosomal recessive disorder. At the molecular and genetic level, ADA deficiency is the most extensively studied of all the congenital immunodeficiency diseases because it was the first of the immunodeficiency diseases in which the molecular defect was identified (10) and the first in which the gene was cloned (11-13). This deep understanding of 
the biochemical and molecular basis of this disease has allowed the development of a number of experimental therapies for ADASCID including the first use of enzyme replacement therapy and the first trial of gene therapy. ADA-SCID is a heterogeneous disorder with clinical presentations ranging from mild (repeated infections with diagnosis after several years of age) to severe (the development of severe infections within several days of birth) (14). ADA catalyzes the conversion of adenosine and dAdo to inosine and deoxyinosine in the normal pathway of purine catabolism and salvage. In the absence of ADA, $2^{\prime}$-dAdo in particular accumulates to high levels in these patients. $T$ cells are the primary site of the toxic effects of ADA deficiency, although $B$ cells may also be severely reduced in number and function (15).

The current treatment of choice for ADA-SCID is an HLAmatched sibling bone marrow transplant. This therapy can be curative for those $20-30 \%$ of children fortunate enough to have an HLA-identical sibling donor, with the best results achieved if the transplant can be performed before the child acquires severe opportunistic infections (16). For children without an HLAidentical sibling, a variety of alternative treatments have been attempted including T-cell-depleted haploidentical bone marrow transplantation, matched-unrelated donor bone marrow transplantation, and enzyme replacement via red cell transfusion, direct enzyme injection, or gene replacement.

In the mid $1970 \mathrm{~s}$, attempts at extracellular enzyme replacement therapy were initiated because $2^{\prime}$-dAdo is freely diffusible across cell membranes. It was reasoned that it might not be necessary to deliver the enzyme into the cells in this disease because the freely diffusible substrate could find its way to the enzyme if a concentration gradient was established. Irradiated red blood cell transfusions as a source of cell-packaged ADA were tried on a number of children (17). A few patients showed some hopeful signs of improved immune function and evidence that dAdo levels were lowered as a result of the treatment. Unfortunately, the majority of ADA-SCID patients experienced none or only minimal immunologic improvement and repeated transfusions created the risk of iron overload and infectious transfusion complications. Nevertheless, the concept of enzyme replacement had been successfully demonstrated, and this led to the development of an enzyme preparation suitable for parenteral injections [bovine ADA conjugated to PEG-ADA (Adagen, Enzon, Inc., So. Plainfield, NJ)] (18). Children receive this drug as an intramuscular injection once or twice weekly; this therapy results in a substantial increase in plasma levels of ADA activity and a marked decrease in $2^{\prime}$-dAdo levels. Most children have derived some clinical benefit from PEG-ADA, with a few of the children demonstrating full immune reconstitution. Other patients respond less well to the enzyme replacement even though their levels of dAdo are decreased as effectively as those in patients who experience greater immune reconstitution. The reasons underlying this differential response remain unexplained.

For those patients without a matched sibling donor, the ideal curative therapy would seem to be the transfer of a normal ADA gene into the patient's own totipotent stem cells. Expression of the normal ADA gene in the totipotent stem cell and its progeny would then be expected to cure all cell lineages for the duration of that individual's life. Based upon the accumulated experience with clinical bone marrow transplantation in this disease, there appears to be a growth advantage for ADA normal lymphoid cells in ADA- patients. This conclusion is based on the observation that transplantation with HLA-matched bone marrow can result in stable lymphoid engraftment and immune reconstitution without the need to use cytoablative preconditioning. This occurred even though the predominant stem cell source in the marrow of the patients who underwent transplantation remains ADA - host-derived cells. Despite this numerical disadvantage, the small number of ADA+ stem cells were able to generate mature peripheral blood $\mathrm{T}$ cells that would reconstitute the patient's immune system (19). Hemopoietic engraftment usually does not occur without preconditioning, but the lack of preconditioning apparently has not significantly affected the immune reconstitution achieved in these patients.

ADA deficiency has a number of characteristics that make it an attractive initial candidate for gene therapy. The gene was isolated in 1983 (11-13), providing almost a decade for researchers to gain experience by investigating the gene, its function, and regulation. HLA-matched sibling bone marrow transplantation in children with ADA-SCID may be curative, even if only the donor T lymphocytes engraft. Thus, gene correction of the same autologous population of cells might also be expected to cure the disease. Furthermore, the ADA gene is a housekeeping gene that is constitutively expressed in cells and does not appear to require sophisticated regulation of its expression. In addition, ADA levels in immunologically normal individuals have been shown to occur over a very broad range. Heterozygous carriers and other individuals have been found with as little as $10 \%$ of the normal mean ADA level in their blood cells, and yet their immune system function is intact (20). At the other extreme, individuals with 50 times the normal mean ADA concentration have been described with mild hemolytic anemia but no immune abnormality (21). Thus, potentially there is a 500-fold range of enzyme concentrations within which we might expect to provide help to these patient's T cells without causing significant unwanted side effects from over- or underexpression of the gene. Because retroviral-mediated gene transfer can result in an extreme variability in gene expression from cell to cell (5), this broad range of expression in immunologically normal subjects might allow wide variation in the effectiveness of ADA gene expression and still result in clinical benefit. Also, because dAdo is freely diffusible, ADA produced in one cell might help restore function in a neighboring cell, even though that cell itself has not acquired the corrective gene. Furthermore, because the experience with allogeneic bone marrow transplantation suggests that ADA normal cells have a selective growth advantage over the uncorrected ADA - cells, gene transfer into only a fraction of the bone marrow stem cell population might be sufficient for the progeny of those cells to completely reconstitute the immune system without the need to eliminate the uncorrected stem cells by cytoablative chemotherapy or radiation treatment.

ADA gene transfer into the totipotent bone marrow stem cell was the initial goal of most studies directed at developing gene therapy for this disease. However, our inability to achieve stable long-term expression of genes transplanted into primate bone marrow with retroviral vectors led us to explore the possibility of using an alternate gene-modified cell population that might be suitable for treatment of this disease. T cells seemed to be a rational choice for this approach for many reasons. Some ADASCID patients, after allogeneic bone marrow transplantation without cytoreductive conditioning, were found to have engrafted with donor $\mathrm{T}$ cells only, yet they were fully immune reconstituted. This suggested that ADA gene-corrected $\mathrm{T}$ cells should have a similar growth advantage in these patients and that correction of the T-cell defect alone might be sufficient to reconstitute their immune function. We knew that retroviralmediated gene transfer could completely correct the metabolic defect in ADA- T cells because of our earlier work with cultured $T$-cell lines from these patients (5), so we knew that we should be able to deliver the corrective gene to the $\mathrm{T}$ cells in culture even if bone marrow gene transfer had not yet been solved. We also had found that the $T$ cells recovered from the blood and bone marrow of ADA-SCID patients appeared to be polyclonal because clones prepared from these $\mathrm{T}$-cell lines were each found to be using a different $\mathrm{T}$-cell receptor $\beta$-chain gene rearrangement pattern (22). Furthermore, the early experience with transfusion therapy and PEG-ADA treatment had indicated that the T-cell lymphopenia in these patients could be substantially reversed by enzyme replacement. The observations on these patients also suggested that these "new" $T$ cells could provide some protective immune function, because the incidence of opportunistic infec- 
tions and failure to thrive appeared to be significantly reduced after institution of enzyme replacement. This clinical improvement was seen even in some patients who failed to demonstrate objective measures of reconstituted specific immune functions, such as antigen-induced T-cell proliferation or the development of positive skin tests. Finally, cultured $T$ cells were being used successfully in the treatment of cancer, so this new approach to cellular therapy had some clinical precedent.

\section{T-LYMPHOCYTE GENE THERAPY FOR ADA DEFICIENCY}

Our preclinical experiments in mice and monkeys demonstrated prolonged survival of genetically altered $\mathrm{T}$ cells with continued expression of the inserted genes in vivo $(23,24)$. Primary T-cell cultures were established from five ADA-SCID patients, and a portion of each culture was genetically corrected after retroviral-mediated transduction with the LASN vector. LASN is a Moloney murine leukemia-based vector, constructed by A. Dusty Miller at the Fred Hutchinson Cancer Center (Seattle, WA), that contains a human ADA gene promoted by the 5'-LTR and an internal SV40 early promoter/enhancerNeoR gene segment, downstream of the human ADA gene (25). Parallel growth of LASN-transduced and nontransduced T-cell cultures demonstrated that all the nontransduced cultures reached senescence and died within a few weeks of the beginning of the culture, whereas the genetically corrected cells continued to grow for months and continued to express the introduced ADA genes (Table 1). These observations suggested that production of ADA in an intracellular location provides a survival advantage to the cells even though the cells were not being challenged with exogenous dAdo in this culture situation.

Ferrari et al. (26) took these observations one step further by transferring ADA-SCID T cells from a child receiving PEG-ADA into immunodeficient BNX mice with and without transduction with a human ADA gene vector. Even though these animals are ADA normal and thus do not have elevated tissue or body fluid levels of dAdo, only the $\mathrm{BNX}$ mice that received $\mathrm{ADA}$ genecorrected cells showed evidence of survival of the patient's $T$ cells. These studies also showed that the surviving human $T$ cells were capable of mediating some $\mathrm{T}$-cell effector functions in vivo. Taken together, these findings suggest that the insertion of a normal ADA gene into the $T$ cell, providing for constitutive intracellular ADA production, gives a survival and functional advantage to those cells beyond that which can be obtained by surrounding the cells with ADA enzyme in the extracellular medium or body fluids.

The Recombinant DNA Advisory Committee of the National Institutes of Health approved a trial of T-cell gene therapy for the treatment of ADA-SCID with LASN-transduced T cells in July 1990. After Food and Drug Administration approval, the first patient was treated on September 14, 1990, and a second child started treatment in January 1991. Each patient had been treated with regular injections of PEG-ADA for at least $2 \mathrm{y}$, and both, despite significant clinical improvement, had documented persisting immunodeficiency before beginning gene therapy. The original child had significant $\mathrm{T}$ lymphopenia, skin test anergy,

Table 1. Effect of ADA gene insertion using LASN retroviral vector on in vitro life-span of primary $T$-cell lines grown from five ADA-SCID patients*

\begin{tabular}{cll}
\hline Cells & Vector & \multicolumn{1}{c}{ Life-span (d) } \\
\hline ADA - T cells & None & $23,24,33,47,49$ \\
ADA - T cells & LASN & $>75,90,>105,111,>198$ \\
\hline
\end{tabular}

* The T cells were originally stimulated with OKT $-3(10 \mathrm{ng} / \mathrm{mL})$ and recombinant IL-2 (200 units) and then maintained in recombinant IL2-supplemented medium without further stimulation with OKT-3. The dates shown represent the day the cultures died. Dates preceded by $>$ indicate cultures that were growing well on the day they were cryopreserved. absent cytolytic T-cell activity for influenza or allogeneic target cells, depressed IL-2 production, and deficient isohemagglutinins and antibody responses. The second patient had presented at an older age and had less severe disease. However, this patient was also deficient in isohemagglutinins and antibodies to recent environmental exposures and had depressed cellular immune responses.

To obtain a broad sample of the immune T-cell repertoire of the patients for genetic correction, it was decided to collect peripheral blood $\mathrm{T}$ cells on each periodically over approximately $1 \mathrm{y}$, genetically correct those $\mathrm{T}$ cells in culture, and then reinfuse the "cured" $T$ cells. Accordingly, every 4-12 wk, the children undergo apheresis to obtain PBMC. The PBMC are placed in culture with OKT-3 (Ortho Pharmaceutical Corp., Raritan, NJ) and recombinant IL-2, which stimulate vigorous T-cell proliferation. Twenty-four $h$ after initiation of culture, the proliferating cells are exposed to the LASN retroviral vector. Using this supernate transduction procedure, $1-10 \%$ of the cultured ADA$\mathrm{T}$ cells acquire and express the ADA gene. After 9 to $12 \mathrm{~d}$ in culture, the $\mathrm{T}$ cells, which have expanded by 50 - to 100 -fold in number, are reinfused i.v. This short-term culture process is used to minimize any tendency of the cultured $\mathrm{T}$ cells to develop the oligoclonality known to occur with long-term in vitro culture. Using $\mathrm{MAb}$ analysis of TCR $\beta \mathrm{V}$ region gene use, we have detected no evidence that oligoclonality has developed in the cell populations infused. No in vitro G418 or $2^{\prime}$-dAdo selection for gene-expressing cells has been used because there is a natural selection process in vitro and presumably in vivo for ADA+ cells.

After seven infusions totaling $7 \times 10^{10} \mathrm{~T}$ cells, the first patient has demonstrated a substantial increase in the number of circulating $T$ cells and the ADA activity in her peripheral blood $T$ cells has increased $>10$-fold. The increase in T-cell numbers and ADA activity has been associated with the development of positive delayed-type hypersensitivity skin tests, isohemagglutinins, cytolytic T cells, and IL-2 production, the regrowth of tonsils, and a decreased number of infectious illnesses (Table 2).

Several critical observations have been made to date during this ongoing study (27). The ADA gene-corrected cells have continued to be detectable in the blood of both children since the first treatment, and these cells have persisted in the blood despite the discontinuation of T-cell infusions for more than 6 mo in the first patient. This demonstrates that the infused ADA gene-corrected $T$ cells may survive for many months and that the survival advantage seen in vitro and with bone marrow transplantation is also true for these gene-corrected $\mathrm{T}$ cells when they are returned to the patients. Importantly, the ADA level in the circulating $T$ cells of patient 1 has also remained elevated, indicating that expression of the introduced gene is also persisting. Both patients have tolerated the treatments without compli-

Table 2. Several measures of immune status of original ADASCID patient* before and after gene therapy

\begin{tabular}{lrr}
\hline \multicolumn{1}{c}{ Parameter } & $\begin{array}{c}\text { Before } \\
\text { gene therapy }\end{array}$ & \multicolumn{1}{c}{$\begin{array}{c}\text { After } \\
10 \mathrm{mo} \dagger\end{array}$} \\
\hline Blood T cells (per $\mu \mathrm{L})$ & 571 & 995 \\
Lymphocyte ADA (units) & 0.6 & 8.3 \\
Phytohemagglutinin response (cpm) & 18500 & 48200 \\
OKT-3 response (cpm) & 700 & 29000 \\
DTH (tetanus toxoid) $\ddagger$ & Negative & $>15 \mathrm{~mm}$ \\
Isohemagglutinin titer & $1: 16$ & $1: 64$ \\
Tonsils & Absent & Present \\
\hline
\end{tabular}

* The patient had been receiving injections of PEG-ADA weekly for 2 y before enrollment in the gene therapy protocol, and this treatment was continued at the standard dose schedule during the $\mathrm{T}$-cell gene therapy trial. For reference, the ADA level of the lymphocytes from the patient's father was 18.3 units.

$\dagger$ Having received seven infusions of autologous ADA gene-corrected $\mathrm{T}$ cells.

$\ddagger$ DTH, delayed type hypersensitivity. 
cation and are able to participate fully in school and social activities. These findings demonstrate that recombinant IL-2expanded autologous ADA gene-corrected $T$ lymphocytes will survive and function in vivo and are able to provide meaningful immune reconstitution beyond that achieved with enzyme replacement alone.

Acknowledgments. In my laboratory, Kenneth W. Culver has conducted most of the preclinical studies as well as shepherded the patients through the clinical protocol. W. French Anderson has been my partner in these studies for the last 10 years or so. A. Dusty Miller, at Fred Hutchinson Cancer Research Center, has made the retrovirus vectors that we have used, and Melvin Berger is following the patients with us. The contributions of all these colleagues are appreciated.

\section{REFERENCES}

1. Anderson WF 1984 Prospects for human gene therapy. Science 226:401-409

2. Report of WHO Sponsored Meeting 1989 Primary immunodeficiency disease Immunodefic Rev 1:173-205

3. Parkman R 1986 The application of bone marrow transplantation to the treatment of genetic diseases. Science 232:1373-1378

4. Miller AD 1992 Human gene therapy comes of age. Nature $357: 455-460$

5. Kantoff PW, Kohn DB, Mitsuya H, Armentano D, Sieberg M, Zweibel JA, Eglitis MA, McLachlan JR, Wiginton DA, Hutton JJ, Horowitz SD, Gilboa E, Blaese RM, Anderson WF 1986 Correction of adenosine deaminase deficiency in cultured human $T$ and $B$ cells by retrovirus-mediated gene transfer. Proc Natl Acad Sci USA 83:6563-6567

6. Kohn DB, Anderson WF, Blaese RM 1989 Gene therapy for genetic diseases. Cancer Invest 7:179-192

7. Wijnaendts L, Le Deist F, Griscelli C, Fischer A 1989 Development of immunologic functions after bone marrow transplantation in 33 patients with severe combined immunodeficiency. Blood 74:2212-2219

8. Williams DA 1990 Expression of introduced genetic sequences in hematopoietic cells following retroviral-mediated gene transfer. Hum Gene Ther 1: 229-239

9. Kantoff PW, Gillio AP, McLachlin JR, Bordignon C, Eglitis MA, Kernan NA, Moen RC, Kohn DB, Yu SF, Karson E, Karlsson S, Zwiebel JA, Gilboa E, Blaese RM, Nienhuis A, O'Reilly RJ, Anderson WF 1987 Expression of human adenosine deaminase in nonhuman primates after retrovirus-mediated gene transfer. J Exp Med 166:219-234

10. Giblett ER, Anderson JE, Cohen F, Pollara B, Meuwissen HJ 1972 Adenosine deaminase deficiency in two patients with severely impaired cellular immunity. Lancet 2:1067-1069

11. Orkin SH, Daddona PE, Shewach DS, Markham AF, Bruns GA, Goff SC, Kelley WN 1983 Molecular cloning of human adenosine deaminase gene sequences. J Biol Chem 158:12753-12756

12. Valerio D, Duyvesteyn MG, Meera Khan P, Guerts van Kessel A, de Waard $\mathrm{A}$, van der $\mathrm{Eb} \mathrm{AJ} 1983$ Isolation of cDNA clones for human adenosine deaminase. Gene 25:231-240

13. Wiginton DA, Adrian GS, Friedman RL, Suttle DP, Hutton JJ 1983 Cloning of cDNA sequences of human adenosine deaminase. Proc Natl Acad Sci USA 80:7481-7485

14. Hirschhorn R 1983 Genetic deficiencies of adenosine deaminase and purine nucleoside phosphorylase: overview, genetic heterogeneity and therapy. Birth Defects 19:73-81

15. Ammann AJ, Hong R 1989 Disorders of the T-cell system. In: Stiehm ER (ed) Immunologic Disorders of Infants and Children. Saunders, Philadelphia, pp 257-315

16. O'Reilly RJ, Keever CA, Small TN, Brochstein J 1989 The use of HLA-nonidentical T-cell-depleted marrow transplants for the correction of severe combined immunodeficiency disease. Immunodefic Rev 1:273-309

17. Polmar SH, Stern RC, Schwartz AL, Wetzler EM, Chase PA, Hirschhorn R 1976 Enzyme replacement therapy for adenosine deaminase deficiency and severe combined immunodeficiency. N Engl J Med 295:1337-1343

18. Hershfield MS, Buckley RH, Greenberg ML, Melton AL, Schiff R, Hatem C, Kurtzberg J, Markert ML, Kobayashi RH, Kobayashi AL, Abuchowski A 1987 Treatment of adenosine deaminase deficiency with polyethylene glycolmodified adenosine deaminase. N Engl J Med 316:589-596

19. Vossen JM 1987 Bone marrow transplantation in the treatment of primary immunodeficiencies. Ann Clin Res 19:285-292

20. Daddona PE, Mitchell BS, Meuwissen HJ, Davidson BL, Wilson JM, Koller CA 1983 Adenosine deaminase deficiency with normal immune function. $J$ Clin Invest 72:483-492

21. Valentine WN, Paglia DE, Tartaglia, AP, Gilsanz F 1977 Hereditary hemolytic anemia with increased red cell adenosine deaminase (45- to 70-fold) and decreased adenosine triphosphates. Science 195:783-785

22. Kohn DB, Mitsuya H, Ballow M, Selegue JE, Barankiewicz J, Cohen A, Gelfand E, Anderson WF, Blaese RM 1989 Establishment and characterization of adenosine deaminase deficient human T-cell lines. J Immunol 142:3971-3977

23. Culver K, Cornetta K, Morgan R, Morecki S, Aebersold P, Kasid A, Lotze M,
Rosenberg SA, Anderson WF, Blaese RM 1991 Lymphocytes as cellular vehicles for gene therapy in mouse and man. Proc Natl Acad Sci USA 88:3155-3159

24. Culver KW, Anderson WF, Blaese RM 1991 Lymphocyte gene therapy. Hum Gene Ther 2:107-109

25. Osborne WRA, Hock RA, Kaleko M, Miller AD 1990 Long-term expression of human adenosine deaminase in mice after transplantation of bone marrow infected with amphotropic retroviral vectors. Hum Gene Ther 1:31-41

26. Ferrari G, Rossini S, Giavazzi R, Maggioni D, Nobili N, Soldati M, Ungers G, Mavilio F, Gilboa E, Bordignon C 1991 An in vivo model of somatic cell gene therapy for human severe combined immunodeficiency. Science 251:1363-1366

27. Culver KW, Berger M, Miller AD, Anderson WF, Blaese RM 1992 Lymphocyte gene therapy for adenosine deaminase deficiency. Pediatr Res 31:149A(abstr)

\section{FLOOR DISCUSSION}

Dr. Gelfand: Can you give us an idea of the phenotypic distribution, cell-proliferative responses, and anything more on these patients?

Dr. Blaese: We are in the process of completing and reviewing all the data that we have collected. The phenotypes of these cells have been very interesting. The first child that we treated had a CD4/CD8 ratio that was profoundly inverted: at the initiation of treatment she had about $80 \%$ CD8 cells. In fact, most of the cells that we found in her circulation after gene correction have been $\mathrm{CD} 8$, so the relative proportion of $\mathrm{CD} 8$ cells has gone up during this time frame despite the significant level of immune reconstitution that we have seen. One of the modifications that we have made in the protocol during the last few months is the use of monoclonal antibody affinity selection to enrich for CD4 cells specifically, in an attempt to achieve a better balance of gene correction than we have seen to date. As for proliferative responses, those have increased. Cytokine production and IL-2 production to a number of the different antigens have increased very substantially when compared with pretreatment levels. The $\mathrm{T}$ cells from our first patient now proliferate quite well to most antigens, although not to all of them. For example, she has a positive skin test, but she does not proliferate to tetanus toxoid in vitro.

Dr. Bergstrom: Have you looked at the peripheral cells in these patients? Can you detect the construct that you have inserted?

Dr. Blaese: Yes.

Dr. Bergstrom: What percentages have you seen?

Dr. Blaese: We are still working on the quantitation of that, so I cannot tell you exactly. The circulating $T$ cells now express ADA levels in the range of $20 \%$ of normal. The mean level of ADA per cell from the introduced gene is about $130 \%$ of normal. So probably about $15 \%$ of the circulating $T$ cells are carrying the corrective gene at this point.

Dr. Schwartz: Did you have a chance to confirm or deny your perception that a polyclonal repertoire of cells is needed, so you had to take them at different times? If you looked at your patients early on, were you able to notice lacunar defects in terms of functional activity? My question is directed at the issue of whether you really need to catch cells at multiple times.

Dr. Blaese: Well, that is one of the dilemmas. The first child that we treated had little in the way of specific immune responses in vitro that we could evaluate. But clearly, as Dr. Hershfield pointed out (in this issue), these children are doing better. They are not dying of opportunistic infections, and clearly the enzyme replacement has done something important. However, in many children we do not see it get to the periphery in the way that we usually measure it. If you make a T-cell line with OKT-3 and IL-2 from a normal individual, it usually lives 4 to 6 mo before it dies at senescence. With the ADA-deficient children, we have found that their T-cell lines usually die within 1 or 2 mo of being established. If you take that same population and put the ADA gene in, the cells survive like normal cells. I think this clearly shows that there is some advantage to having the enzyme produced intracellularly. I do not know how that matches with other people's views of what ADA is doing, but it certainly has made a difference in survival. Claudio Bordignon has done the same 
experiment in an Italian patient: he took the ADA-deficient $\mathrm{T}$ cells, gave them to immunodeficient mice, and then showed that these ADA-deficient cells disappear within a few days. If you gene-correct those cells and put them into the immunodeficient mouse, they are able to function quite well for a number of months. Obviously those mice do not have a problem with ADA; they have low dAdo levels. This also suggests that there is an advantage to having the gene product (ADA) produced intracellularly.

Dr. Ochs: That is the crux of the matter. Do you think you are doing more than just a very nicely targeted ADA-replacement therapy? Are you really doing gene therapy?

Dr. Blaese: We are using genes to target the production of ADA to the T cells.

Dr. Ochs: So are you just a notch higher in sending the ADA to the place where it is needed?

Dr. Blaese: How is that different from gene therapy? It is a semantic argument. I think that the treatment seems to be beneficial to the children, and I think the ADA is coming from the gene we are putting in.

Dr. Ochs: One way to solve that, at least on a practical level for those of us who take care of these patients, is to select a patient who does not respond to PEG-ADA. We have seen a patient from Steve Douglas who would be an ideal case, and I have talked to you about this before. This is the kind of patient I think we really need to push to gene therapy, because we should not forget that all these patients Dr. Hershfield is treating are on PEG-ADA, and I hear different interpretations. I hear that they do very well on PEG-ADA, or they did relatively well before gene transfer therapy. I would strongly recommend that those of you who are on the trigger with these patients select at least one patient who does not respond to PEG-ADA.

Dr. Blaese: We studied Steve Douglas' patient extensively in vitro. That child's $\mathrm{T}$ cells do grow polyclonally in our system, and it is very easy to get the gene in and get it expressed in high levels. Steve has been reluctant to enter this patient in the protocol, and so we have not been able to do gene transfer therapy. There are other patients that we have evaluated. One was the second patient in Dr. Hershfield's series. Unfortunately, that child now has an absolute lymphocyte count of only 75 , and it is very hard for us to get enough $T$ cells from that patient to do the gene therapy by our current technique. We certainly want to do it. But that is another problem: if a patient is severely deficient, we are not going to get enough peripheral $T$ cells to be able to gene-correct. I am somewhat concerned that if we take apheresed lymphocytes from a child who has a very restricted circulating T-cell repertoire, out in the periphery, we may end up with oligoclonal T-cell expansion. This, in turn, could cause autoimmunity such as hemolytic anemia as a result of imbalance in the immunoregulatory $T$ cells.

Dr. Gelfand: And that is not withstanding the fact that you are also counting on the patient's cells to respond to OKT-3 plus IL-2 to increase the efficiency of gene transfer. You have many obstacles to overcome.

Dr. Sorenson: What criteria are you going to use to stop giving enzyme replacement in these patients? Also, how feasible is this procedure economically? We all have other patients waiting. Can you take 15 patients in the near future and do gene transfer?

Dr. Blaese: We have been prohibited from talking about stopping PEG-ADA by the Committees. They did not even want to have that in the protocol as a possibility, so we will have to go back to the National Committees for approval. We are not yet ready, and probably will not be for some time, to propose stopping the enzyme until we have a pretty good feel for the nature of the repertoire that we have developed and can estimate how long these cells persist in the circulation. We also must try to demonstrate whether we have any holes in the repertoire. I think it is likely that as soon as we stop PEG-ADA treatment we will freeze the T-cell repertoire; that is, unless we get the gene into the stem cell. The PEG-ADA may be needed to continually generate repertoire. Our plan was to try to cure the antigenspecific $T$ cell when it is out there in the circulation and give it a long life-span.

Dr. Gelfand: I would like to come back to Dr. Ochs' question, which I do not think was answered. In the individual $T$ cells that have been successfully transfected, you are providing enzyme replacement. Would those cells now have an effect on other cells in the circulation? Are you providing ADA to help cells that do not have ADA within them to draw the dAdo out of the nontransfected cells, much like giving it in the plasma? Is there a point at which you can achieve sufficient numbers of transfected cells to help those cells that are not transfected?

Dr. Blaese: That is a crucial question, and my gut feeling is probably no. Children who have undergone HLA-identical sibling bone marrow transplantation without cytoreduction do not, in general, recover their own $\mathrm{T}$ cells. If they do appear, it is late after transplantation and only at very low levels. Most of those circulating cells continue to be the donor cells. Therefore, getting a normal level of ADA expression in $\mathrm{T}$ cells alone does not seem to provide enough ADA activity to allow endogenous host $\mathrm{T}$ cells to come back.

Dr. Gelfand: So the argument remains that the cell that has endogenous ADA activity in it does better than the cell exposed to ADA in the plasma. And I guess that is still part of the argument.

Dr. Blaese: Well, that is what the transfer experiments in the mouse suggest, and our cell line data also suggest that. I think the relative immune response rate that we have seen in our patients also suggests that these children are doing somewhat better than they were before. That is not to say that the PEGADA is not important. It is critical to our approach that they do well enough on PEG-ADA to allow us to try this approach to gene therapy.

Dr. Ballow: For those patients that have severe lymphopenia, do you anticipate a two-step approach in which you might take bone marrow first and then go to peripheral blood?

Dr. Blaese: The protocol that we have submitted for consideration at the March Recombinant DNA Advisory Committee meeting will look at CD34-selected peripheral stem cells, and we are going to be using a retrovirus vector different from the one that we use with $T$ cells. We will continue treatment with $T$ cells, but we'll add a couple of peripheral stem cell treatments. Then later on we will be able to distinguish, by polymerase chain reaction, which of the populations is working. We do not know if we can get the gene into the stem cell, but I think it is an important experiment to do now that we are confident that this is a reasonably safe procedure.

Dr. Strober: Have you considered inserting (along with the retrovirus vector) a gene segment that decodes the $\mathrm{T}$-cell receptor for a particular antigen, and then getting expression of that $\mathrm{T}$ cell receptor on the surface of the cells that are transfected with the retrovirus? Could you then bump up the number of $T$ cells by simply immunizing the patient?

Dr. Blaese: That would not work in this disease. It would be potentially very useful if you wanted to have $T$ cells make factor VIII or factor IX for hemophilia, for instance. Then you could come back and hit them with the antigen to continually reexpand the cells engineered to produce the clotting factors. However, I am not sure that picking one or even a handful of specificities would be particularly wise in ADA-SCID. We want to get polyclonal immune reconstitution in these children. It is conceivable that if you made a suppressor $\mathrm{T}$ cell to a particular antigenic epitope you would shut down not only that specificity but other cells with different specificities, and this would result in the loss of the polyclonal repertoire.

Dr. Hershfield: I have some thoughts, which I expressed earlier, that I think need to be raised again. The first patient that you treated was started without doing one control that might have been considered. That control would be to culture the patient's cells in fetal calf serum with a mouse cell line, expand them with 
IL-2, and then give them back to the patient without the ADA gene. You showed some dramatic increases in lymphocyte counts after one or two infusions with relatively small numbers of cells in which an even smaller percentage were expressing the ADA gene. I would argue that, at least at that level, the effects that you saw may have had nothing at all to do with the ADA gene. Are you planning to do that kind of control in another patient?

Dr. Blaese: We discussed that approach at great length. We did not do that control because I felt that the greatest risk of this protocol was not the gene transfer part, but rather giving the lymphocytes back. My concern was based on the experience we have had with lymphocyte infusions in patients receiving tumor infiltrating lymphocyte therapy, for example. Since I felt there was some risk, I thought that this control was not the appropriate thing for me to do to make this experiment tidy. The reason we have stopped therapy now and followed these children (the first one for 6 mo without treatment) is to try to get a feeling for the longevity, to let those noncorrected cells disappear from the circulation as much as possible. It is not tidy, but I still think we will get the same answer by evaluating these patients. In the future, we may do some lymphocyte infusions, but I do not think it is really justified from what we have seen of the rapid catabolism of that population when we stop treatment at a time when the proportion of gene-corrected cells is still low.

Dr. Gupta: Considering you would have to do repeated injections, have you tried just giving some patients IL-2 in vivo? Would that cut down on your need to give repeated injections of lymphocytes?

Dr. Blaese: Again, what we are trying to do is correct the repertoire, and we think the only way to do that is to get the gene into the cells.

Dr. Gupta: You have to come in repeatedly. If you were keeping them on low-dose IL-2 maintenance, would that cut down your need to come in to infuse the treated lymphocytes?
Dr. Blaese: I do not think IL-2 is needed or relevant in this particular setting. These patients do not seem to have any trouble making IL-2 on their own, and these cells do not seem to have any trouble responding if they stay around and survive long enough. There may be a patient in whom IL-2 could work. For instance, Dr. Hershfield reported a case of a child who made normal ADA concentrations when the $T$ cells were cultured in IL-2, so this was a gene defect that was somehow reversed on exposure to IL-2. But that is a different subset of these patients, and a different protocol.

Dr. Hershfield: PEG-ADA is enormously expensive. It has a use for which there is no substitute: it can be given to sick children who are not candidates for bone marrow transplantation. The two patients you have discussed today responded very well to PEG-ADA, and they continue to receive PEG-ADA. They also appear to have responded in a substantial way to the treatment that you are giving, and I think there is a question in many people's minds about whether it is really a substitute for PEG-ADA. I think it is very important to stop PEG-ADA in those patients, and I think it is very important to do it in a timely fashion. In the beginning, I thought it was essential that those children stay on PEG-ADA because I assumed that children who would be treated first would be those who had deteriorated clinically on PEG-ADA. That was not the case. It troubles me to hear you say that you are doing without phase II and phase III, when I know that phase III is the phase in which you stop PEG-ADA.

Dr. Blaese: No, that is not so. We were not given permission by the Recombinant DNA Advisory Committee to go on to phase III. We will stop PEG-ADA when we are ready. I do not think we have enough data, and I am not comfortable with it yet. These are children, not mice. I do not believe that we should expose them to additional risk until we have more data to help us make the correct decision. 